\title{
EXPLORAÇÃO E SOFRIMENTO MENTAL DE PROFESSORES: UM ESTUDO NA REDE ESTADUAL DE ENSINO DO PARANÁ
}

\author{
EXPLOITATION AND MENTAL SUFFERING AMONG TEACHERS: A STUDY IN \\ THE STATE SCHOOL SYSTEM IN THE STATE OF PARANÁ, BRAZIL
}

\author{
EXPLOTACIÓN Y SUFRIMIENTO MENTAL DE LOS DOCENTES: UN ESTUDIO EN \\ LA RED ESTATAL DE ENSEÑANZA DEL ESTADO DE PARANÁ, BRASIL
}

Guilherme Souza Cavalcanti de Albuquerque ${ }^{1}$

\author{
Lucas Nathã Almeida Lira² \\ Isaías dos Santos Junior ${ }^{3}$ \\ Ricardo Luiz Chiochetta ${ }^{4}$ \\ Paulo de Oliveira Perna ${ }^{5}$ \\ Marcelo José de Souza e Silva ${ }^{6}$
}

Resumo A reestruturação do mundo do trabalho tem exercido forte impacto sobre as condições de vida e saúde da classe trabalhadora. Os professores têm sofrido, assim como os demais trabalhadores, a precarização do trabalho, entre outras consequências da acumulação flexível, com o aumento das exigências sem o incremento suficiente dos recursos necessários para o desempenho do trabalho. A intensa elevação do sofrimento mental dos docentes parece estar ligada às novas condições de trabalho. Visando a fornecer subsídios para o enfrentamento dessa questão, realizou-se pesquisa buscando verificar a associação entre a elevação da exploração no trabalho dos docentes e o sofrimento mental. Efetuou-se estudo transversal por meio da plataforma Limesurvey, em que 1.201 professores da rede estadual responderam a dois questionários on-line: o Self-Reporting Questionnaire-20 e outro, elaborado pelos pesquisadores, sobre as condições de trabalho dos docentes. Carga horária semanal, número de alunos por turma e número de turmas por professor apresentaram associação com transtornos psíquicos menores. A associação de número de alunos por turma com a presença de transtorno psíquico menor foi estatisticamente significativa. Concluiu-se que a prevalência de casos indicativos de distúrbios psíquicos é muito elevada entre os professores, havendo indícios de associação com diversas formas de exploração no trabalho docente.

Palavras-chave saúde do trabalhador; sofrimento mental; saúde do professor; educação.
Abstract The reorganization of the world of labor has a strong impact over the life and health statuses of the working class. Teachers, as well as other workers, have been going through a process of precarization of labor, among other consequences of flexible accumulation, with the increase in the requirements without a sufficient increase in the resources that are needed in order to perform the work. The significant increase in mental suffering among teachers seems to be connected to the new working conditions. With the goal of providing elements in order to face this issue, we developed a research with the aim of observing the association between the increase in exploitation in the work of the teachers and mental suffering. We performed a crosssectional study using the Limesurvey online survey tool, in which 1,201 teachers of the state school system answered 2 online questionnaires: the Self-Reporting Questionnaire-20 and another one, developed by the researchers, about the working conditions of the teachers. The weekly working hours, the amount of students per classroom and the amount of classes of students per teacher showed an association with minor psychological disorders. The association between the amount of students per classroom and the presence of a minor psychological disorder was statistically significant. We concluded that the prevalence of cases that indicate psychological disorders is very high among teachers, and there are signs of an association with many different kinds of exploitation in the work of teachers.

Keywords worker health; mental suffering; teacher health; education. 


\section{Introdução}

O trabalho do professor constitui, na atualidade, uma atividade de risco, pois a docência é uma das profissões mais estressantes no âmbito do capitalismo contemporâneo (Souza e Leite, 2011), caracterizado pelo extremo aumento da exploração da força de trabalho e pela produção maciça de enfermidades, entre as quais se destacam os transtornos mentais (Breilh e Tilleria, 2009).

No atual modo de acumulação do capital, denominado por Harvey (2008) de acumulação flexível, os processos produtivos são marcados pela exigência da realização de atividades muito diversas por um mesmo trabalhador, conforme o momento e a demanda de produção. Trata-se de um regime produtivo voltado para atender à maior flexibilidade dos padrões de consumo e, portanto, marcado, também, por maior flexibilidade dos processos, produtos e organização do trabalho.

No mundo do trabalho passam a predominar frenéticas inovações comerciais, tecnológicas e organizacionais, destinadas a atender com agilidade às permanentes mudanças da demanda.

Para os trabalhadores, a flexibilidade nos contratos de trabalho, o trabalho temporário e a terceirização, entre outros, resultam na precarização das relações trabalhistas, na redução dos salários, no desemprego estrutural e no enfraquecimento das lutas sindicais.

Os processos de trabalho experimentaram, também, a intensificação da incorporação tecnológica, acentuando, em muito, a transferência do conhecimento e da virtuosidade do trabalhador para a máquina, para a tecnologia.

O trabalho flexibilizado cada vez mais prescinde do trabalhador que domina as bases científicas das operações. A forma de produção flexível na qual o conhecimento científico está cada vez mais incorporado à tecnologia, às máquinas e aos protocolos de procedimentos produtivos requer apenas um trabalhador que se adapte ágil e permanentemente às constantes transformações.

Como já demonstrava Marx, o enriquecimento do trabalho empobrece o trabalhador:

quanto mais o trabalhador produz, menos tem para consumir; que quanto mais valores cria, mais sem-valor e indigno ele se torna; quanto mais bem formado o seu produto, tanto mais deformado ele fica; quanto mais civilizado seu objeto, mais bárbaro o trabalhador; que quanto mais poderoso o trabalho, mais impotente o trabalhador se torna; quanto mais rico de espírito o trabalho, mais pobre de espírito e servo da natureza se torna o trabalhador (Marx, 2008, p. 82).

A polarização da formação da força de trabalho se intensifica. A uma parcela muito reduzida de trabalhadores se viabiliza o acesso a um tipo de educação que permite a apropriação dos fundamentos científicos necessários 
para a compreensão da realidade para além de sua aparência (a compreensão da gênese dos fenômenos e das leis gerais que os determinam), o que amplia o seu poder de intervenção teleológica sobre a natureza. No outro polo, a grande massa de trabalhadores tem acesso tão somente a uma educação superficial, suficiente apenas para torná-los aptos a operar os processos produtivos planejados e geridos pela parcela privilegiada.

Portanto, para a formação da força de trabalho necessária para a realização do trabalho flexibilizado, o processo educativo se simplifica, pois não exige mais a transmissão das bases científicas sobre as quais se sustentam as diversas atividades laborais. Dessa forma, se a educação se simplifica, consequentemente a formação do professor pode ser simplificada, uma vez que este também não precisa dominar o conhecimento científico acumulado pela humanidade, já que não lhe cabe mais transmiti-lo.

Nesse panorama, o professor deixa, na maioria das vezes, de ser aquele que transmite o conhecimento historicamente produzido pela humanidade e sistematizado na escola, passando a assumir a função de auxiliar o aluno, futuro trabalhador, a alcançar ou manter uma condição de empregabilidade. Se, por um lado, como força de trabalho, em algum aspecto o valor de uso do professor se modifica, também seu valor se reduz, pois sua reprodução, agora mais simples, exige menor tempo de trabalho social.

Essa situação causa sofrimento para o professor, tanto pela evidência da perda de substância de seu trabalho (pela menor produção de valor de uso) quanto pela perda de seu próprio valor como força de trabalho, o que o obriga a se submeter a piores condições laborais e a maior grau de exploração para manter a remuneração que lhe permita um nível de vida razoável. Disso resulta o que Esteve (1999) denomina de mal-estar docente, um tipo de doença social causado pela falta de apoio da sociedade ao professor, provocando-lhe o desencantamento com o trabalho.

Diversos estudos abordam, na atualidade, a questão do sofrimento mental do professor; no entanto, o fazem de perspectivas predominantemente psicológicas e biomédicas, marcadas pelos limites analíticos da clínica ou da epidemiologia tradicional, de cunho positivista, sem considerar sua determinação econômica.

Diante disso, propõe-se no presente estudo analisar o sofrimento mental docente como expressão particular de seu modo de vida, sobredeterminado pela ordem social capitalista contemporânea. Visando a fornecer subsídios para a proposição de ações de melhoria das condições de trabalho, com redução dos níveis de sofrimento mental relacionados à docência, neste estudo se estabeleceu como objetivo expor a relação entre o grau de exploração do professor e o sofrimento mental. 


\section{Percurso: da representação do fenômeno à síntese de sua determinação}

Trata-se de um estudo que se iniciou com um levantamento transversal de dados atinentes ao sofrimento mental dos professores, relacionando-os com sua exploração no trabalho, assim como com os processos mais gerais de determinação de sua saúde/doença, mediante uma interpretação materialista histórico-dialética da realidade.

A pesquisa contou com a participação voluntária de 1.201 professores da rede pública de ensino da Secretaria de Estado da Educação do Paraná, após divulgação pelos meios de comunicação da APP-Sindicato - entidade dos professores -, assim como por jornais e rádios do estado do Paraná.

Trabalhou-se com os dados referentes às respostas dos professores a questionários disponíveis on-line, na plataforma Limesurvey. Os questionários utilizados foram o Self-Reporting Questionnaire-20 (SRQ-20), para mensuração de transtornos psíquicos menores, ${ }^{7}$ e outro, elaborado pelos pesquisadores, sobre as condições de trabalho dos professores. Os resultados do SRQ-20 podem variar de 0 (nenhuma probabilidade de transtornos, ou negativo) a 20 (extrema probabilidade, ou positivo).

Foram tomados como indicadores da condição de trabalho dos professores a carga horária semanal, o total de horas-aula, o número de turmas e o número médio de alunos por turma.

Para a análise estatística, utilizaram-se os testes qui-quadrado, exato de Fisher e de Kruskal-Wallis. Fez-se uso do software R, versão 3.2.2. Considerouse nível de significância de 5\%, sendo estabelecido significativo se $p<0,05$. A partir disso foram calculadas as razões de chances de adoecer, relacionadas às condições analisadas.

Para a compreensão da determinação dessas condições de trabalho, procurou-se analisar as mudanças ocorridas na educação, na atualidade, e suas repercussões sobre o trabalho dos professores. Por fim, para se entender a gênese das mudanças no campo da educação, procurou-se compreender os direcionamentos contemporâneos da economia capitalista.

$\mathrm{O}$ presente estudo não contou com financiamento e foi aprovado pelo Comitê de Ética da Universidade Federal do Paraná mediante o parecer 223.652.

\section{As faces da exploração dos professores}

Dentre os participantes da pesquisa, $926(77,1 \%)$ eram do sexo feminino e $275(22,9 \%)$ do sexo masculino, com $84(6,99 \%)$ tendo idades entre 19 e 30 anos, $338(28,14 \%)$ entre 31 e 40 anos, $543(45,21 \%)$ entre 41 e 50 anos, 197 $(3,76 \%)$ entre 51 e 60 anos e $14(1,17 \%)$ mais de 60 anos. Quanto à formação, $1(0,08 \%)$ concluiu pós-doutorado, $4(0,33 \%)$ concluíram doutorado, $90(7,49 \%)$ mestrado, $1.035(86,18 \%)$ especialização, $6(0,50 \%)$ aperfeiçoa- 
mento, $38(3,16 \%)$ curso superior completo e $1(0,08 \%)$ tem curso superior incompleto, o que mostra que a maioria dos professores continua estudando mesmo após a conclusão do ensino superior, buscando aprimoramento. Quanto ao salário, $2(0,17 \%)$ recebem até 1 salário mínimo, $26(2,16 \%)$ de 1 a 2 salários mínimos, $139(11,57 \%)$ de 2 a 3 salários mínimos, $267(22,23 \%)$ de 3 a 4 salários mínimos e 741 (61,70\%) mais de 4 salários mínimos. Quanto ao vínculo empregatício, $83(6,91 \%)$ participantes não eram concursados e $1.093(91 \%)$ concursados, sendo que $2(0,17 \%)$ eram professores há menos de 1 ano, $23(1,91 \%)$ de 1 a 3 anos, $48(4 \%)$ de 3 a 5 anos, $185(15,40 \%)$ de 5 a 10 anos, $393(32,72 \%)$ de 10 a 20 anos e $525(43,71 \%)$ há mais de 20 anos. No momento da pesquisa, 64 (5,33\%) não estavam lecionando, $75(6,24 \%)$ trabalhavam de 3 a 19 horas por semana em sala de aula, $480(39,97 \%)$ de 20 a 29 horas, $273(22,73 \%)$ de 30 a 39 horas, $267(22,23 \%)$ de 40 a 49 horas e $17(1,41 \%)$ mais de 50 horas. Pode-se perceber que a população participante é constituída, predominantemente, por professoras que trabalham há bastante tempo como docentes que assumem grande carga horária dentro de sala de aula.

Os resultados demonstram que apenas $12,46 \%$ dos professores que participaram do estudo trabalham nas escolas da Secretaria de Estado da Educação em regime de 20 horas semanais, 78,53\% têm carga horária semanal de 40 horas e 1,11\% cumprem carga de 60 horas semanais.

A relação da carga horária semanal com a presença de transtornos psíquicos menores (TPMs), identificados pelos resultados do SRQ-20 (Tabela 1), demonstrou uma associação direta: ao passo que $72,97 \%$ daqueles que trabalham 20 horas semanais apresentam SRQ-20 positivo, esta cifra se eleva para $76 \%$ dos professores que trabalham 40 horas semanais e $78 \%$ daqueles com carga horária de 60 horas semanais.

Tabela 1

\begin{tabular}{llll}
\hline \multicolumn{2}{l}{ Carga horária semanal x \% de SRQ-20 negativo e positivo, para professores da rede estadual do Paraná, 2015.} \\
\hline Critério & Carga horária & SRQ-20 negativo & SRQ-20 positivo \\
\hline Carga horária semanal x SRQ-20 & $20 \mathrm{~h}$ & $27,63 \%$ & $72,97 \%$ \\
& $40 \mathrm{~h}$ & $24 \%$ & $76 \%$ \\
& $60 \mathrm{~h}$ & $22 \%$ & $78 \%$
\end{tabular}

Fonte: os autores.

Embora essa associação não tenha sido estatisticamente significativa, ressaltem-se os fatos de que 904 professores $(75,27 \%)$ apresentaram positividade no SRQ-20 e de que a positividade ascendeu com o aumento da carga horária.

Quanto ao número de turmas por professor, 16,06\% deles trabalhavam com 1 a 5 turmas, 45,38\% trabalhavam com 6 a 15 turmas e 4,59\% chega- 
vam a assumir 20 ou mais turmas. Esse dado evidenciou, também, grande sobrecarga, especialmente porque as atividades docentes não se restringem àquelas realizadas na sala de aula, pois implicam também o preparo de aulas, elaboração e correção de provas, exercícios e trabalhos, entre outros. Apesar disso, a correlação dos dados do SRQ-20 positivo e negativo com o número de turmas por professor não evidenciou uma associação estatisticamente significativa, o que sugere que outros aspectos, como a carga horária e o número de alunos por turma, tenham exercido maior influência sobre sua saúde mental.

O número médio de alunos por turma foi de aproximadamente 33, sendo que $42,96 \%$ dos professores trabalhavam com 15 a 30 alunos por turma, $52,41 \%$ com 31 a 40 e $2,63 \%$ com 41 a 60 .

A associação entre SRQ-20 e o número de alunos por turma (Tabela 2) apresentou-se estatisticamente significativa $\left(\mathrm{p}=0,002, \mathrm{I}^{2}\right)$, havendo correspondência entre SQR-20 positivo e maior número de alunos por turma.

Tabela 2

Número de alunos por turma x \% de SRQ-20 negativo e positivo, para professores da rede estadual do Paraná, 2015.

\begin{tabular}{llll}
\hline Critério & Alunos/turma & SRQ-20 negativo & SRQ-20 positivo \\
\hline No de alunos/turma $\times$ SRQ-20 & $15-30$ alunos & $29,33 \%$ & $70,67 \%$ \\
& $31-40$ alunos & $20,5 \%$ & $79,5 \%$ \\
& $41-60$ alunos & $26,31 \%$ & $73,69 \%$ \\
\hline
\end{tabular}

Fonte: os autores.

A análise do trabalho dos professores demonstrou uma carga horária muito elevada. Além do fato de $88 \%$ deles trabalharem 40 ou mais horas semanais nas escolas, o trabalho docente exige, de todos, destinação de extensa carga horária para além da jornada oficialmente computada. Segundo os dados coletados, a correção de provas e trabalhos, o lançamento de notas e frequências, o preparo das atividades e a elaboração de relatórios exigem, invariavelmente, a extensão da jornada, invadindo o tempo de descanso, do convívio familiar ou da realização de afazeres domésticos. A grande maioria dos professores acaba, ainda, assumindo uma jornada extra de trabalho para os cuidados com a casa e a criação dos filhos.

Além disso, é preciso ressaltar que quase todos os professores gastam de uma a duas horas diárias no percurso entre a residência e a escola.

A possibilidade de realizar atividades de preparo de aulas, correção de provas e cômputo de frequências, entre outras, durante a jornada de trabalho, tem sido lentamente conquistada pela categoria, à custa de grande desgaste, devido ao enfrentamento conflitivo com os gestores estaduais, que paulatinamente têm introduzido a lógica privatista nas relações com os servidores públicos, em busca de maior produtividade. Além disso, deve-se salientar também que, atualmente, grande parte dos professores se vincula à escola sob 
regime de trabalho não estatutário, com um contrato temporário, o que, além de reduzir seus direitos trabalhistas, os coloca em situação de vulnerabilidade nos processos de enfrentamento de classe.

O trabalho nas escolas estaduais coloca os professores em contato direto com uma população cujos direitos de cidadania são frequentemente negados. Muitos dos alunos são filhos de famílias pobres, com grande dificuldade de acesso a moradia adequada, transporte, segurança, lazer, serviços de saúde, saneamento, arte, entre outros produtos da civilização. Ou seja, trata-se de uma população violentada pela sociedade desigual da qual participa perifericamente, exposta a diversos tipos de violência.

Dessa forma, os estudantes assumem, com frequência, um comportamento agressivo e de desrespeito às normas estabelecidas para o convívio escolar, o que exige do professor uma dificílima tarefa educativa, situação agravada pelo insuficiente apoio institucional, diante da precariedade em que as escolas hoje se encontram.

\section{O comum e o específico da exploração encontrada}

Nos tempos atuais, observa-se um número crescente de transtornos mentais e comportamentais associados aos diversos ramos de trabalho. A Organização Mundial da Saúde (OMS) estima que cerca de 30\% dos trabalhadores ocupados, na população geral, sofrem de transtornos mentais de menor gravidade, ao passo que cerca de $5 \%$ a $10 \%$ são acometidos por transtornos mentais graves (Vasconcelos, 2010).

Em relatório global lançado em 2017, a OMS estima que o número de pessoas que vivem com depressão aumentou 18\% entre 2005 e 2015 . O relatório indica, também, que há 322 milhões de pessoas vivendo com esse transtorno mental no mundo, sendo a prevalência maior entre as mulheres. Ainda segundo a publicação, a depressão atinge 5,8\% da população brasileira (11.548.577) e os distúrbios relacionados à ansiedade afetam 9,3\% (18.657.943) das pessoas (WHO, 2017).

Na presente pesquisa, identificou-se que $75,27 \%$ dos professores participantes apresentaram transtornos psíquicos menores, correlacionados à carga de trabalho (associação estatisticamente não significativa) e ao número de alunos por turma (associação estatisticamente significativa). Deve-se atentar para o fato de que a relação estatisticamente não significativa observada entre a carga horária e o sofrimento mental pode se dever ao fato de não terem sido computadas as muitas horas trabalhadas fora da sala de aula, que aumentam, em muito, a exploração dos professores.

No contexto aqui estudado, o número médio de alunos por turma foi de aproximadamente 33 , sendo que mais de $55 \%$ das turmas continham um número de alunos superior a 30. Pesquisa reunindo 31 países da Organização 
para a Cooperação e Desenvolvimento Econômico (OCDE) registra que o tamanho médio das turmas é de 21 alunos nas séries iniciais e de 24 nas séries finais, revelando que as turmas escolares no Brasil recebem mais alunos do que deveriam (Último Segundo, 2010).

No estudo conduzido por Porto e colaboradores (2006) em Vitória da Conquista, Bahia, constatou-se que 53\% dos professores submetidos a 'alta exigência' no trabalho apresentavam distúrbio psíquico, com maior prevalência no sexo feminino (46\%).

Em pesquisa conduzida por Silva (2015) em prontuários de 2000 a 2012 relativos a docentes de uma universidade pública federal, foram constatados 146 registros com diagnóstico de "transtornos mentais e comportamentais"; o diagnóstico prevalente foi o de "episódios depressivos", com 41 casos (quase um terço dos registros). Nas entrevistas, as condições de trabalho foram adjetivadas como "insuficientes", "péssimas" e "inexistentes".

Em outra pesquisa, realizada no estado da Bahia entre 1996 e 2007, as prevalências de transtornos mentais comuns no trabalho docente foram elevadas, atingindo, pelo menos, um quinto dos entrevistados (Carvalho e Araújo, 2007). O estudo de Carvalho e Araújo demonstra, ainda, que características da docência tais como trabalho repetitivo, insatisfação no desempenho das atividades, desgaste nas relações professor-aluno, ambiente intranquilo, falta de autonomia no planejamento das atividades, ritmo acelerado de trabalho, desempenho das atividades sem materiais e equipamentos adequados e salas inadequadas associaram-se, positivamente, em níveis estatisticamente significantes, aos transtornos mentais, o que corrobora os resultados da presente pesquisa.

Estudo de Cortez e colaboradores (2017), pesquisando artigos científicos publicados entre 2003 e 2016 sobre o tema da saúde do professor, encontrou 69 trabalhos elegíveis para análise. Quanto aos sintomas psíquicos relacionados, prevaleceram regressão, exaustão emocional, nervosismo, estresse e insônia, síndrome de burnout, transtornos psíquicos e afastamentos do trabalho, prejuízos na criatividade e nos domínios socioemocionais, negação, despersonalização e distorções na percepção da importância e do esforço dedicado ao trabalho - o trabalho visto como um sacerdócio - que predispõem o docente a se submeter a riscos e a sobrecarga. O mesmo estudo, focalizando a categoria 'aspectos contextuais do trabalho docente', agrupou trabalhos sobre a dupla jornada, excesso de tarefas e dificuldades de relacionamento entre famílias e escola, aumento da carga de trabalho, demanda por índices institucionais elevados, alta pressão por desempenho e baixo nível de controle das tarefas, desordem em sala de aula, ruídos, hostilidade entre alunos, desvalorização pessoal e salarial, problemas institucionais e baixa remuneração, excesso de alunos em sala e infraestrutura escolar inadequada para o trabalho. 
A simples associação desses fatores, no entanto, não desvela a gênese do processo de adoecimento dos professores. Os estudos sobre a saúde mental são, predominantemente, fundamentados na perspectiva da biologia, da psicologia e da ergonomia, o que tem limitado a compreensão dos fenômenos estudados.

Para Souza e Leite (2011, p. 1.106),

o trabalho docente é compreendido como uma atividade repetitiva, fragmentada e executada com a imposição de ritmos intensos. As análises sobre as condições de trabalho são fortemente marcadas pela autopercepção dos professores, sendo praticamente inexistentes os estudos empíricos sobre as reais condições de trabalho em escolas. Da mesma forma, há também poucos estudos sobre os reflexos da organização e da gestão do trabalho na saúde dos professores e os estudos sobre saúde, de forma geral, buscam os sintomas (autopercepção) e suas patologias e acabam por estabelecer orientações para a promoção e prevenção (estudos prescritivos).

Segundo Granda e Breilh (1989) e Breilh (2006), para avançar na compreensão da gênese do adoecimento, é preciso investigar os processos particulares, atinentes ao modo de vida imposto aos diversos grupos (classes ou frações de classes), que determinam suas condições singulares de existência; trata-se de processos sobredeterminados pelos processos estruturais de reprodução social.

Aos professores das escolas aqui estudadas impõem-se processos de trabalho com alto grau de exploração.

No modo de produção capitalista, todo processo de trabalho deve estar voltado para a valorização do capital. Alguns processos de trabalho estão diretamente ligados a esse fim, outros indiretamente. Aqueles que estão diretamente ligados constituem o trabalho produtivo, produtor de mais-valia ou mais-valor. Os trabalhos não ligados diretamente à valorização do capital são denominados de trabalho improdutivo, pois não produzem mais-valor.

A produção de mais-valor ocorre pela exploração do trabalhador pelo capitalista, que se apropria de parte do valor que o trabalho do primeiro produz. Tal exploração pode ser exercida ao se obrigar o trabalhador a trabalhar por um tempo de trabalho superior ao relativo a seu salário, ou seja, estendendo a jornada de trabalho, o que Marx denomina de mais-valor absoluto; a exploração também pode ser exercida pela intensificação do trabalho, o que permite a extração de uma quantidade maior de mais-valor no mesmo tempo de trabalho, o que Marx denomina mais-valor relativo. O mais-valor assim produzido só se realizará, no entanto, com a venda da mercadoria (Marx, 2013).

O presente estudo refere-se a um trabalho do tipo improdutivo, não produtor de mais-valor, o trabalho de professores do ensino público. Isso não implica, no entanto, que tal trabalho não contenha exploração dos trabalhadores que o realizam. 
É com valores recolhidos mediante a cobrança dos impostos que o Estado paga os serviços públicos, como a educação. Como tais recursos provêm da divisão do mais-valor produzido pelos trabalhos produtivos, quanto mais se gastar para o pagamento dos serviços públicos, menor o lucro dos capitalistas. É por esse motivo que, também nos serviços públicos, o trabalhador é explorado ao máximo: não para produzir mais-valor, mas para gastar menor parcela do mais-valor produzido socialmente.

Os processos de trabalho dos professores que participaram da presente pesquisa apresentam aspectos de evidente exploração: seja pela jornada de trabalho, que em alguns casos chega a 60 horas - fora o tempo de deslocamento e do trabalho doméstico -, seja pela intensificação do trabalho, observada pelo elevado número de turmas que um mesmo professor assume, assim como pelo elevado número de alunos por turma.

Segundo Cruz e colaboradores (2010), a docência é uma área que exige atuação para além dos limites formais da jornada de trabalho e do espaço físico dos estabelecimentos de ensino. O professor se obriga a desenvolver atividades no próprio lar para corrigir provas, preparar aulas, estudar e pesquisar, sacrificando tempo de sua vida pessoal para o convívio com familiares e amigos, ou simplesmente para fruição de tempo para seu lazer.

Outras vezes, seu papel se estende, ainda, para além de sua área de atuação específica, sendo levado a desempenhar papéis de assistente social, psicólogo, enfermeiro, entre outros (Vieira e Fernandes, 2011).

Todas essas atribuições e exigências levam o docente a viver, a cada dia, os sentimentos decorrentes do desgaste psicológico e do estresse físico, o que o impele a um ciclo degenerativo da saúde.

Para Esteve (1999), essas condições de trabalho contribuem para que o professor desenvolva sentimentos negativos como ansiedade, angústia, exaustão profissional e desmotivação, podendo conduzir até a situações extremas de atitudes desumanizadas e de insensibilidade no exercício de sua profissão.

Massa e colaboradores (2016) afirmam que a persistência de fatores estressores decorrentes do processo de exploração da força de trabalho pode levar à denominada síndrome de burnout. Essa síndrome é uma reação à tensão emocional crônica, própria das exigências impostas ao docente e a outros profissionais ao lidar com outras pessoas, produzindo gradativamente a despersonalização e a falta de envolvimento pessoal com o trabalho. Em seu estudo, os autores destacam ainda que o professor está presente em todas as fases da vida do aluno, tendo que conviver com as peculiaridades e complexidades deste, além das suas próprias. Outros autores, como Codo (2006), chamam esse quadro de síndrome da desistência, pois o trabalhador vai perdendo os motivos que costumavam gratificá-lo em seu trabalho. 
No Brasil, é perceptível a ocorrência desse quadro na atividade do professor, acrescido da desvalorização que a categoria docente vem sofrendo nas últimas décadas, com políticas públicas que cobram atualização dos conhecimentos do professor com ínfima contribuição real para sua melhoria. Em geral, a qualificação do docente fica por sua própria conta, demandando desembolso pessoal, levando-o ao constrangimento financeiro e à restrição de suas escolhas de lazer. Além disso, as oportunidades de qualificação à disposição dos professores nem sempre primam pela qualidade (Martins, 2010).

O estudo de Carvalho e Araújo (2007) demonstrou, também, que o trabalho realizado em situação de alta exigência - envolvendo altas demandas psicológicas e baixo nível de controle - estava associado à maior prevalência de transtornos mentais comuns.

\section{Conclusão}

Evidenciou-se, com a presente investigação, que a prevalência de casos indicativos de distúrbios psíquicos é muito elevada entre os professores e que há indícios da associação desta prevalência com diversas formas de exploração no trabalho.

Carga horária semanal, número de turmas por professor e número de alunos por turma apresentaram relação positiva para a ocorrência de sofrimento mental. Embora somente a associação entre o número de alunos por turma e a presença de sofrimento mental tenha se apresentado estatisticamente significativa, deve-se considerar que a análise de tais fatores tomados isoladamente em relação aos processos que os determinam padece de todas as limitações das interpretações unicausais e multicausais das doenças.

O enfrentamento consistente dos problemas advindos do trabalho docente requer a identificação dos processos protetores e destrutivos da saúde desses profissionais, para o combate do que é deletério e o fomento do que é protetor. Tais ações, de prevenção e promoção da saúde, exigem, ao mesmo tempo, que se tenha como horizonte a intervenção na estrutura social, que é aquela que determina, em última instância, a ocorrência dos processos particulares da vida desse grupo de trabalhadores, que determinam, por sua vez, os processos individuais de saúde e doença expressos nos corpos dos professores. A ação tradicional, circunscrita ao corpo e ao comportamento dos indivíduos, intervém apenas nas consequências, ou seja, na superfície dos fenômenos, deixando intacta sua gênese. 


\section{Colaboradores}

Lucas Nathã Almeida Lira participou da concepção e delineamento do projeto, da análise e interpretação dos dados e da redação do artigo e aprovação da versão a ser publicada. Isaías dos Santos Junior participou da análise e interpretação dos dados e da redação do artigo e aprovação da versão a ser publicada. Ricardo Luiz Chiochetta participou da análise e interpretação dos dados e da redação do artigo e aprovação da versão a ser publicada. Guilherme Souza Cavalcanti de Albuquerque participou da concepção e delineamento do projeto, da análise e interpretação dos dados e da redação do artigo, revisão crítica e aprovação da versão a ser publicada. Paulo de Oliveira Perna participou da análise e interpretação dos dados, da revisão crítica do artigo e aprovação da versão a ser publicada. Marcelo José de Souza e Silva participou da concepção e delineamento do projeto, da análise e interpretação dos dados e da revisão crítica do artigo e aprovação da versão final a ser publicada.

Resumen La reestructuración del ámbito laboral ha ejercido un fuerte impacto sobre las condiciones de vida y salud de la clase trabajadora. Los docentes, así como los demás trabajadores, han sufrido la precarización del trabajo, entre otras consecuencias de la acumulación flexible, con el aumento de las exigencias sin el incremento suficiente de los recursos necesarios para la ejecución del trabajo. El intenso aumento del sufrimiento mental de los docentes parece estar relacionado a las nuevas condiciones de trabajo. A fin de ofrecer recursos que puedan servir como contribución para enfrentar esta cuestión, se realizó esta investigación buscando constatar la asociación entre el aumento de la explotación de los docentes en su trabajo y el sufrimiento mental. Se efectuó un estudio transversal por medio de la plataforma LimeSurvey, en la que 1.201 docentes de la red estatal respondieron dos cuestionarios en línea: el Self-Reporting Questionnaire-20 y otro, elaborado por los investigadores, sobre las condiciones de trabajo de los docentes. La carga horaria semanal, el número de alumnos por clase y el número de clases por docente, presentaron asociación con trastornos psíquicos menores. La asociación de número de alumnos por clase con la presencia de trastorno psíquico menor fue estadísticamente significativa. Se concluyó que la prevalencia de casos indicativos de disturbios psíquicos es muy alta entre los docentes, existiendo indicios de asociación con diversas formas de explotación en el trabajo docente.

Palabras clave salud del trabajador; sufrimiento mental; salud del docente; educación. 


\section{Notas}

${ }^{1}$ Universidade Federal do Paraná, Departamento de Saúde Comunitária, Curitiba, Paraná, Brasil. <guilherme.albuquerque.ufpr@gmail.com>

Correspondência: Universidade Federal do Paraná, Departamento de Saúde Comunitária, Rua Padre Camargo, 280, $7^{\circ}$ andar, Alto da Glória, CEP 80060-240, Curitiba, Paraná, Brasil.

${ }^{2}$ Universidade Federal do Paraná, Curitiba, Paraná, Brasil.

$<$ lucaslira@hotmail.com>

${ }^{3}$ Universidade Federal do Paraná, Curitiba, Paraná, Brasil.

<pro.isaias@gmail.com>

${ }^{4}$ Universidade Federal do Paraná, Curitiba, Paraná, Brasil.

$<$ ricardo.cht@hotmail.com $\geq$

${ }^{5}$ Universidade Federal do Paraná, Departamento de Enfermagem, Curitiba, Paraná, Brasil. <popernal@gmail.com>

${ }^{6}$ Universidade Federal do Paraná, Setor de Ciências da Saúde, Departamento de Saúde Coletiva, Curitiba, Paraná, Brasil.

$<$ marcelojss@gmail.com>

${ }^{7}$ Sintomas não psicóticos, como insônia, fadiga, irritabilidade, esquecimento, dificuldade de concentração e queixas somáticas.

\section{Referências}

BREILH, Jaime. Epidemiologia crítica: ciência emancipadora e interculturalidade. Rio de Janeiro: Editora Fiocruz, 2006.

BREILH, Jaime; TILLERIA, Ylonka. Aceleración y despojo en Ecuador: el retroceso del derecho a la salud en la era neoliberal. Quito: Universidad Andina Simón Bolivar, Ediciones Abya-Yala, 2009.

CARVALHO, Fernando M.; ARAÚJO, Tânia. M. Condições de trabalho docente e saúde na Bahia: estudos epidemiológicos. Educação \& Sociedade, Campinas, v. 30, n. 107, p. 427-449, maio-ago. 2007. Disponível em: <http://www. cedes.unicamp.br>. Acesso em: 9 set. 2014.

CODO, Wanderley (coord.). Educação: carinho e trabalho. 4. ed. Petrópolis: Vozes; Brasília: Confederação Nacional dos Trabalhadores em
Educação, Universidade de Brasília/Laboratório de Psicologia do Trabalho, 2006.

CORTEZ, Pedro Afonso et al. A saúde docente no trabalho: apontamentos a partir da literatura recente. Cadernos de Saúde Coletiva [on-line], Rio de Janeiro, v. 25, n. 1, p. 113-122, 2017.

CRUZ, Roberto Moraes et al. Saúde docente, condições e carga de trabalho. Revista Eletrónica de Investigación y Docencia, Jaén, $\mathrm{n}$. 4, p. 147-160, jul. 2010.

ESTEVE, José. M. O mal-estar docente: a sala de aula e a saúde dos professores. Bauru: Edusc, 1999.

GRANDA, Edmundo; BREILH, Jaime. Saúde na sociedade: guia pedagógico sobre um novo enfoque do método epidemiológico. 2. ed. 
São Paulo: Cortez, Instituto de Saúde; Rio de Janeiro: Abrasco, 1989.

HARVEY, David. Condição pós-moderna: uma pesquisa sobre as origens da mudança cultural. 17. ed. São Paulo: Loyola, 2008.

MARTINS, Lígia. M. O legado do século XX para a formação de professores. In: MARTINS, Lígia M.; DUARTE, Newton (orgs.). Formação de professores: limites contemporâneos e alternativas necessárias. São Paulo: Cultura Acadêmica, 2010. p. 13-31.

MARX, Karl. Manuscritos econômico-filosóficos. São Paulo: Boitempo Editorial, 2008.

MARX, Karl. O capital: crítica da economia política. Livro I: O processo de produção do capital. São Paulo: Boitempo, 2013.

MASSA, L. D. B. et al. Síndrome de burnout em professores universitários. Revista de Terapia Ocupacional da Universidade de São Paulo, v. 27, n. 2, p. 180-9, maio-ago. 2016. Disponível em: <file://C:/Users/fast/Downloads/104978220577-1-PB\%20(1).pdf>. Acesso em: $10 \mathrm{de}$ nov. 2017.

PORTO, Lauro A. et al. Associação entre distúrbios psíquicos e aspectos psicossociais do trabalho de professores. Revista de Saúde Pública, São Paulo, v. 40, n. 5, p. 818-826, 2006.

SILVA, Eduardo P. Adoecimento e sofrimento de professores universitários: dimensões afetivas e ético-políticas. Psicologia: teoria e prática, São Paulo, v. 17, n. 1, p. 61-71, jan.-abr. 2015.

SOUZA, Aparecida N.; LEITE, Marcia P. Condições de trabalho e suas repercussões na saúde dos professores da educação básica no Brasil. Educação \& Sociedade, Campinas, v. 32, n. 117, p. 1.105-1.121, out.-dez. 2011. Disponível em: < http://www.redalyc.org/articulo.oa?id=87321425011 > ISSN 0101-7330>. Acesso em: 01 out. 2014.

ÚLTIMO SEGUNDO. Turmas nas escolas brasileiras são mais numerosas, diz OCDE. 2010. Disponível em: <http://ultimosegundo.ig.com. br/educacao/turmas-nas-escolas-brasileirassao-mais-numerosas-diz-ocde/n1237772647725. html>. Acesso em: 13 nov. 2017.

VASCONCELOS, Antônio. G. Jurisdição e sofrimento mental: o trabalho é simplesmente locus de manifestação ou um fator concorrente ou constitutivo dos transtornos mentais? Revista do Tribunal Regional do Trabalho da $3^{a}$ Região, Belo Horizonte, v. 51, n. 81, p. 411-436, jan.-jun. 2010.

VIEIRA, Raquel Arrieiro; FERNANDES, Cassia Pires. Avaliações externas em foco: percepções e efeitos para o trabalho docente. Educação em Perspectiva, Viçosa, v. 2, n. 1, p. 119-132, jan.-jun. 2011.

WHO (WORLD HEALTH ORGANISATION). Depression and other common mental disorders: global health estimates. 2017. Disponível em: <http://who.us9.list-manage.com/track/ click? u=a6b34fbd46b688a84a907el6d\&id= 969f835fdc\&e=27de531d3a $>$. Acesso em: 12 de nov. 2017.

Recebido em 03/04/2017. Aprovado em 11/12/2017. 